UMR 5824

$$
\begin{array}{r}
\text { 93, chemin des Mouilles } \\
69130 \text { Ecully - France } \\
\text { Maison de r'Université, Bâtiment B } \\
10, \text { rue Trefilerie } \\
42023 \text { Saint-Etienne cedex 02 - France } \\
\text { http://www.gate.cnrs.fr } \\
\text { gate agate.cnrs.fr }
\end{array}
$$

\title{
Kenneth Arrow, moral obligations, and public policies
}

\author{
Susumu Cato, Adrien Lutz
}

\begin{abstract}
:
Kenneth Arrow is a founder of the social choice theory as well as a main developer of modern theories of market economies. Moral obligations and social norms are at the core of Arrow's ethical considerations to understand and overcome his well-known impossibility theorem of preference aggregation. Interestingly, he thinks that moral obligations and social norms are very important to overcome failures of market economies. Also, he proposed some interaction between public policies and evolution of social norms. Here, we can find a consistent and systematic thinking of Arrow's ethical considerations, which might be overlooked in spite of its importance. We believe that Arrow has political philosophy (or a theory of justice), which is quite useful to understand recent developments of behavioral economics and theories of non-market economies. Arrow's thought is totally different from Amartya Sen and John Rawls, which are dominant in modern theories of justice. Arrow's approach can shed some new lights on the subject of social justice.
\end{abstract}

\section{Keywords:}

Efficiency, Equity, Social justice, Moral obligation, Social choice, Communitarianism

\section{JEL codes:}

B22, D62, D63

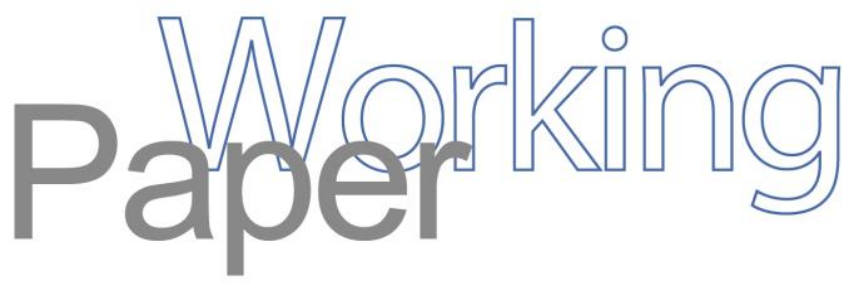




\title{
Kenneth Arrow, moral obligations, and public policies* $^{*}$
}

\author{
Susumu Cato ${ }^{\dagger}$ and Adrien Lutz ${ }^{\ddagger}$
}

January 4, 2019

\begin{abstract}
Kenneth Arrow is a founder of the social choice theory as well as a main developer of modern theories of market economies. Moral obligations and social norms are at the core of Arrow's ethical considerations to understand and overcome his well-known impossibility theorem of preference aggregation. Interestingly, he thinks that moral obligations and social norms are very important to overcome failures of market economies. Also, he proposed some interaction between public policies and evolution of social norms. Here, we can find a consistent and systematic thinking of Arrow's ethical considerations, which might be overlooked in spite of its importance. We believe that Arrow has political philosophy (or a theory of justice), which is quite useful to understand recent developments of behavioral economics and theories of non-market economies. Arrow's thought is totally different from Amartya Sen and John Rawls, which are dominant in modern theories of justice. Arrow's approach can shed some new lights on the subject of social justice.
\end{abstract}

Keywords: Efficiency, Equity, Social justice, Moral obligation, Social choice, Communitarianism

JEL clasification: B22, D62, D63

*We thank Marc Fleurbaey and Kian Mintz-Woo for helpful comments and suggestions. We also thank Princeton University for its hospitality. This work was supported by JSPS (26870477).

$\dagger$ Institute of Social Science, the University of Tokyo, 7-3-1, Hongo, Bunkyo-ku, Tokyo 113-0033, Japan.

${ }_{\ddagger}^{\ddagger}$ Univ Lyon, UJM Saint-Etienne, GATE L-SE UMR 5824, F-42023 Saint- Etienne, France. 


\section{Introduction}

Amartya Sen points out in On Ethics and Economics (1987), that ethical concerns were at the core of the classical political economy of Adam Smith, J.S. Mill, Karl Marx, and other early moral philosophers. Because human beings regard others, ethics, which is interested in value judgment, is one of the origins of economic analysis (Smith 1759). In spite of the importance of ethical thinking, the "technological" or "engineering" approach has dominated modern economic analysis after the Second World War.

According to Sen (1987), a revival of the ethical approach is necessary for economics. Indeed, Sen provides substantial works on this issue. For example, Sen (1970) incorporates the concept of "rights" in the theory of social choice. Recently, Sen (2009) also argues that the approach of social choice is a useful framework of social justice and argues for the advantages of its comparative nature over the transcendental approach of political philosophy developed by Jean-Jacques Rousseau and Immanuel Kant, and more recently, by John Rawls, Robert Nozick, and so on. According to Sen (2009), social choice theory can be a foundation of more practical and realistic reforms of our world, which is far from the ideal state.

As well recognized, considerations of rights and freedoms are fundamental factors in Sen's economics and philosophy, which are opposed to the general approach of welfarism. Also interested in freedom and social choice, Arrow emphasizes the importance of "obligations," "norms," or "responsibilities", over rights in a series of his works on general equilibrium, moral hazard, environmental issues, education, and so on. ${ }^{1}$ These are certain types of ethical considerations, but Arrow's thinking is different from that of Sen and many other social choice theorists. In this paper, we attempt to describe the entire picture of Arrow's ethical considerations in a theory of justice.

The motivation of this paper is twofold. First, it aims to show a comprehensive view of Arrow's normative thinking. As is well known, Arrow's famous impossibility theorem has been discussed by many political philosophers and other normative theorists. ${ }^{2}$ Although Arrow is one of the greatest economists in our history, his philosophy has not been synthesized because his normative arguments are scattered in many articles and most of his works are mathematical. As this study shows, his normative arguments are quite consistent and shed light on the general approach of social justice.

Second, this study aims to offer a coherent explanation of systems of

\footnotetext{
${ }^{1}$ For example, see Arrow ([1969] 1983) for an argument on the general equilibrium, Arrow (1963b, 2001, 2006) for moral hazard, Arrow (1993) for education, and Kinzig, et al. (2013) for environmetal issues.

${ }^{2}$ See, for example, Hook (1967).
} 
moral obligations. Recently, many experimental/empirical studies, including works on neuroscience, have shown that people care about moral obligations and norms. In particular, feelings about fairness and justice are shown to be quite strong and influential on human behavior (Konow, 2003). Development of a positive analysis of this issue is game changing. However, it is necessary to construct a normative analysis that can complement the positive analysis. Obviously, moral obligations and social norms have complicated natures because they are not just given, and can also be affected by human behavior, history, and culture of societies. Our investigation of Arrow's arguments might explain his entire views on social justice, and show how we can unify the positive and normative approaches of moral obligations.

Many authors have recognized Arrow's interests in moral obligations and social norms (Andreoni, 1990; Elster, 1989; Putnam, 2001; Bowles, 2016). Indeed, his works on moral obligations and social norms have been quite influential in the recent development of experimental economics and behavioral approach of altruism. ${ }^{3}$ However, it is noteworthy that Arrow's thinking about moral obligations is not just about altruistic behaviors or evolutionary games. His argument is also about formulation of objectives and public policies. We believe that his entire picture on moral obligations is quite helpful for understanding how public policies work.

The rest of this paper is organized as follows. Section 2 examines the role of moral obligations in the problem of formulating social values. Section 3 shows that Arrow has a similar idea to communitarianism about the place of moral obligations. We also argue how moral obligations contribute equality in society. Section 4 discusses the relationship between moral obligations and public policies. Section 5 concludes this paper.

\section{Moral Obligations in Social Choice}

Arrow (1963a) proves the general (im)possibility theorem in his book Social Choice and Individual Values. According to the theorem, it is not possible to construct normatively desirable social values from individual values. Formally, Arrow considers a mapping that assigns a social preference to a profile of individual preferences. The mapping is called a social welfare function or a constitution. Four axioms are imposed as normatively desirable requirements for this mapping: the unrestricted domain, the Pareto principle, the independence of irrelevant alternatives, and non-dictatorship. The Arrow theorem states that there exists no social welfare function that satisfies the

\footnotetext{
${ }^{3}$ See, for example, Fehr and Schmidt (2006) and Bowles (2016).
} 
four axioms. ${ }^{4}$

Each of Arrow's axioms has a normative significance. The unrestricted domain requires that some social judgment be made for all combinations of individual preferences. This axiom allows diversity of individuals' values. The Pareto principle requires that if a state is preferred to another state for every member of the society, then the former state is socially better than the latter state. In other words, the consensus among people is respected. The independence axiom requires that the social ranking between two alternatives depends only on individual rankings between the two alternatives. That is, this axiom states that information about two alternatives is sufficient to determine the ranking between them, and other information is unnecessary. Thus, it is associated with how much information we need to formulate a social preference. In this sense. individual values are efficiently used as informational input in a collective process. ${ }^{5}$ Non-dictatorship excludes an extreme case in which there is an individual who control social preferences. Since dictatorship is extremely inequitable, this axiom is a very weak requirement of anonymity/equality. ${ }^{6}$ In summary, they are principles of diversity, unanimity, informational efficiency, and equity.

There are two major interpretations of the theorem. First, it can be interpreted as a result showing the limitation of welfare economics, in which there is no ideal way to construct social indifference curves over the set of allocations. This interpretation put the theorem in the league of the notable contributions of Bergson (1938), Kaldor (1939), Hicks (1939), and Samuelson (1983). In particular, some researchers argue that the theorem is about the death of the Bergson-Samuelson school of welfare economics, which assumes the existence of social values. ${ }^{7}$ Although Arrow's original formulation of the theorem cannot be applied to standard economic problems because of

\footnotetext{
${ }^{4}$ The Arrow theorem here is the version used in the second edition (Arrow, 1963a). In the original theorem, positive association of social and individual values and citizens' sovereignty are imposed instead of the Pareto principle, and the domain is restricted in a certain way. Arrow's modification follows Blau (1957) pointing out an error of the theorem, and the modification has become widespread.

${ }^{5}$ Accordding to Suzumura (2005, p. 13), "[the independence axiom] requires that the Arrow social welfare function must be informationally efficient in that, in deciding whether one social state is better than, or worse than, or indifferent to another social state, it is necessary and sufficient to know how individuals rank just these two alternative social states vis-à-vis each other." Some authors, including Campbell and Kelly (2000), Fleurbaey, Suzumura, and Tadenuma (2005), and Cato (2014), extend the axiom in order to incorporate broader infomation.

${ }^{6} \mathrm{~A}$ strong form of equity is called anonymity, which requires that social values are invariant for any shuffle of names of individuals.

${ }^{7}$ Fleurbaey and Mongin (2005) provides an overview about this subject.
} 
the unrestricted domain axiom, the theorem can be extended to economic environments. The second interpretation of the theorem is that it implies that there exists no ideal democratic decision process or voting method. Therefore, the theorem can be regarded as a general result in the line of works by two scholars around the time of the French Revolution: Jean-Charles de Borda and Marquis de Condorcet, as well as British authors, including Edward J. Nanson and Charles Dodgson (Lewis Carroll). Arrow suggests that both interpretations hold and regards the theorem as a synthesis of the two traditional approaches of aggregation of individual values. ${ }^{8}$

Famous scholars working on the new welfare economics reject the first interpretation. ${ }^{9}$ According to Samuelson (1967), "I export Arrow to politics because I do not believe that he has proved the impossibility of the traditional Bergson welfare function of economics..." (Samuelson, 1967, p. 42). For Samuelson, the theory of social choice is the mathematical theory of the voting mechanism. In addition, Samuelson claimed that Arrow's social welfare function is different from Bergson's one and requires another name, that is, "constitution." The main problem for Samuelson is the difference between single-profile and multi-profile setting: a Bergson welfare function needs only one preference profile, which is fixed, but an astronomically large number of preference profiles should be handled in Arrow's framework. Arrow takes the name suggested by Samuelson, but never took Samuelson's idea to export the theorem to politics. ${ }^{10}$ For Arrow (as well as Sen), social choice theory is relevant for welfare economics.

Moreover, Arrow himself accepts a broader interpretation of social choice as a theory of normative judgment for human society. Arrow (1977) states that "it can be interpreted to provide one aspect of any normative judgment about interpersonal relations which is based, in some measure, on the satisfaction of individual needs" (Arrow, 1977, p. 607). In this broad interpretation, "[a] theory of justice, such as Rawls's...is an example of social choice falling within the purview of the general theory" (Arrow, 1977, pp. 607-608).

If this interpretation is accepted, we need to consider Arrow's theorem more seriously because it implies a difficulty of formulating general social

\footnotetext{
${ }^{8}$ Arrow also mentions the decision making process in a firm. In 1946, he considers how the objective of the firm is formulated if there are multiple owners. See Arrow (1983, p. 2).

${ }^{9}$ See Little (1952), Bergson (1954), and Samuelson (1967), as well as an interview with Samuelson by Suzumura (2005). This interview shows that Samuelson does not change his opinion about Arrow's theorem. For some differences between options by Bergson and Samuelson, see footnote 4 of Suzumura (2005).

${ }^{10}$ See, for example, Arrow (1978).
} 
justice and human values. Do we need to give up formulating them? The answer is negative. The theorem shows that there is some trade-off between various fundamental values, such as efficiency, equity, stability, and so on, although each of them looks self-evident at first glance. Arrow's impossibility theorem can be a stepping stone for a more sophisticated theory of social justice and human values, and the axiomatic theory of social choice serves as a comparative and practical framework of normative judgments. ${ }^{11}$

How can people reach their possibility of social justice or human values? As is well known, Arrow's theorem is very tight in the sense that a possibility theorem can be obtained if we drop some of his axioms or collective rationality is relaxed. That is, there are many ways of escaping from impossibility. Among others, Arrow himself suggests two ways to overcome the difficulty: (1) the domain restriction and (2) extended sympathy. ${ }^{12}$

First, we can obtain possibility results when the unrestricted domain is relaxed. In particular, if we restrict our attention to a domain with singlepeaked preferences, the majority voting method can generate consistent social preferences, and it is a social welfare function that satisfies the axioms other than the unrestricted domain. Arrow arrived at this possibility result in the spring of 1948 in the Cowles Foundation for Research in Economics at Yale University, but found that the work by Black (1948), which proved the exactly same result, was published in the Journal of Political Economy. ${ }^{13} \mathrm{In}$ his original Social Choice and Individual Values in 1951, Arrow discusses the underlying meaning of the possibility result, which comes from restricting the domain. The key is "similarity" among individuals in society; as mentioned previously, the meaning of the unrestricted domain is diversity among individuals. Since individual preferences are connected in a certain way, we can find similarities of individual attitudes in single-peaked preferences. Indeed, it has been widely recognized that similarities can resolve the impossibility of collective decision-making (Inada 1969; Sen and Pattanaik 1969; Kramer 1973). As a general remark, Arrow writes:

"[S]ome values which might give rise to such similarity of social attitudes are the desires for freedom, for natural power, and for equality; likeness in individual tastes, by its very nature, leads

\footnotetext{
${ }^{11}$ Social choice theorists, including Arrow (1974b), Sen (1999), and Suzumura (2002), discuss the positive roles of Arrow's theorem on welfare economics or broader approaches of social justice. The final remark of Arrow (1974b) is "I hope that others will take this paradox as a challenge rather than as a discouraging barrier."

${ }^{12}$ Recent works on welfare economics have shown that relaxing the independence axiom provides a wide range of possibilities of reasonable welfare criteria. See, for example, Fleurbaey and Maniquet (2011).

${ }^{13}$ See an interview with Kelly (1987).
} 
to likeness in desires for social alternatives. Somewhat less direct in its social implication is the desire for prolongation of life, which we may take to be one of the most universal of all human values"(Arrow, 1963a, pp. 74-75).

Arrow mentions "natural" tendencies among individuals. Individuals in the same society also share the language, cultures, moral codes, and convention, which can help individuals to have similar tastes. These social norms matter and affect "desires for freedom, for natural power, and for equality."

Furthermore, Arrow proposes another way to overcome the impossibility theorem without formal analysis. People in society inevitably have concerns for others, which can lead us to sympathy. As is well known, sympathy is a main problem of Hume's Treatise and Adam Smith's Moral Sentiments. For Arrow (1974a), sympathy is "feeling oneself to be in the other one's place" (Arrow, 1974a, p. 25). This type of sympathy can be regarded as an extension of an individual preference. A formal analysis of extended sympathy is conducted by Suppes (1966). Formally, the following form of individual judgment is considered: for individual $\mathrm{A}$, state $x$ in the position of individual B is better than state $y$ in the position of individual C. This is called an extended preference of individual A. Clearly, A imagines the positions of $\mathrm{B}$ and $\mathrm{C}$.

As shown by Sen, a certain natural judgment under extended sympathy, which is called the grading criterion, is not compatible with the Pareto principle if the domain is not restricted. Indeed, Sen (1970) introduces a restriction to the domain, the axiom of identity, which requires that extended preferences are identical among individuals. Under this axiom, if, for some individual $\mathrm{A}$, state $\mathrm{x}$ in the position of individual $\mathrm{B}$ is better than state $\mathrm{y}$ in the position of individual $\mathrm{C}$, then so this is true for all individuals in society. That is, the following simple form of comparison can be made among people under the axiom of identity: "state $\mathrm{x}$ is better (or worse) for me than state $\mathrm{y}$ is for you" (Arrow, 1963a, p. 114). This is what Arrow considers and is "certainly one way of approaching the notion of an appropriate income distribution" (Arrow, 1963a, p. 114).

Clearly, complete unanimity is the case with extreme similarities among individuals. We do not need complete unanimity but we need a certain type of similarities to resolve the difficulty of the collective-decision-making with extended sympathy.

Later studies, especially by Hammond (1976), demonstrate that the extendedsympathy framework of social choice can serve as a basis of the Rawlsian difference principle and other related criteria. If the axiom of identity is satisfied, the criterion, which highlights the advantages of the individual in 
the worst position, is derived from modified Arrow's axioms and an equity axiom (Hammond equity principle). This implies that certain types of moral sentiments and similarities lead us to equitable social values.

These two approaches show that social norms and sympathy among individuals can be devices for the possibilities of formulating social justice and human values. The point is that neither norms nor sympathy are objects of social choice: they occur prior to social choice. In the first approach, the restriction to preferences is given from outside of collective decision processes. Similarity of tastes is determined by human nature and social norms. There is no way to determine them collectively. If there is a collective-decision process that constructs such factors, we obtain another impossibility result in the meta-stage by applying Arrow's theorem again to it. Thus, social norms or sympathy give us a possibility result only if it is not an object of social choice.

In the second approach, sympathy can be regarded as a type of interpersonal comparability. As argued by Binmore (2005), the kind of interpersonal comparability that is possible is a consequence of evolutionary processes of social norms. To compare utilities of different individuals, one needs a measurement that is common among individuals. Binmore (2005) discusses a possibility that individuals sharing cultures and morals can have sympathy each other, and they share such a measurement because of evolution based on cultures and morals. There is no collective decision process for interpersonal comparisons. In both approaches, moral judgment or social norm, which evolves outside of collective decision processes, is presumed to make the decision process possible.

\section{Moral Judgments before Social Values}

As explained in Section 2, Arrow has the idea that the fundamental subject of social choice is essentially the same as that of A Theory of Justice of John Rawls. In addition, Rawls (1971) mentions the relationship between welfare economics/social choice and political philosophy, although Rawls thinks that the framework of welfare economics/social choice is narrower than his general framework (Rawls, 1971, pp. 258-259). This is quite natural because both theories of justice and welfare economics are branches of moral philosophy. ${ }^{14}$ In this section, we discuss methodological positions of moral judgments in their theories.

\footnotetext{
${ }^{14}$ Sen (2009) emphasizes the difference between social choice and Rawlsian approach to justice.
} 
In Rawlsian theories of justice, the principles of justice should be chosen in the original position. ${ }^{15}$ At this level of decision making, people do not know much about themselves (the veil of ignorance). They know neither their concrete preferences nor their moral principles, which they want to or have to follow. After the basic structure of institutions is established given the principles of justice, people can have their own moral senses and judgments. Therefore, moral obligations would be determined after fundamental collective decision-making or making social values. In other words, there is no moral obligation before the principles of justice.

This fundamental presumption in Rawls is what communitarians attacked mainly in 1980s (e.g., Alasdair MacIntyre, Michael Sandel, Charles Taylor, and Michael Walzer). That is, the original position as an Archimedean point seems to guarantee the universal nature of the principles of justices. Collective decision making is identical to the single decision making behind the veil of ignorance because everyone has exactly the same information. In the words of Sandel (1982), this is the unencumbered self. According to Rawls (1971), "the self is prior to the ends affirmed by it" (Rawls, 1971, p. 560). Communitarians have considered that the conception of the person is meaningless and over-individualized behind the veil of ignorance because people, who attempt to choose the principle, must live in a particular society with a particular culture and a particular history. People's identity comes from their community. For communitarians, a "common good" shared by people has a crucial role in formulating a kind of principles. Such a common good is given by the context of a society, and thus, each society can have each doctrine of social justice. A history, a context, and a pre-existing common good should matter. According to Rawls, the liberal state cannot answer to cultural or particular interests so far. Indeed, such a state has to be neutral and fair, and should respect moral individualism as well.

As is well known, Sen criticizes Rawls's theory of justice in many respects. Sen $(1980,2009)$ refutes the idea of the original position and considers primary goods to be replaced with capabilities. However, we can say that Sen has the same position as Rawls with respect to thought about pre-existing common goodness, although there are differences that perhaps originate in their different methodologies. In other words, Sen is against the idea of communitarians; he considers that people's reasons are more significant than communitarian values in human life (Sen, 1999). ${ }^{16}$ According to Sen (1999),

\footnotetext{
${ }^{15}$ Harsanyi (1953) and Vickrey (1945) offer ideas similar to Rawls's original position. However, they do not justify the Rawlsian-type maximin. Harsanyi explicitly derives the average utilitarian principle. See also Binmore (2005) who examines how we can obtain the maximin from the original position.

${ }^{16}$ See Anderson (1991).
} 
people can conduct reasonable activities beyond their community, and make agreements through public deliberation. In other words, history, context, or pre-existing common good is not necessarily a foundation for social justice.

Now, we turn to Arrow's thinking about common good. The place of moral obligations in Arrow's argument seems to be sympathetic with communitarian thought. In 1967, when Arrow discussed the nature and significance of his impossibility theorem at a symposium, he emphasized the role of moral obligations in making social values: "I interpret moral obligation as the carrying out of agreements which may, however, be implicit" (Arrow, [1967] 1983, p. 79). That is, moral codes and social norms in society can be helpful for formulating social values and collective decision making. Moreover, implicitness are a crucial feature of them. For instance, in the case of blood donation, Arrow writes: "there is an implicit social contract such that each performs duties for the other in a way calculated to enhance the satisfaction of all" (Arrow, 1972, p. 348). Then, even though many moral obligations are unclear or at least implicit, it constitutes an important part of social values.

Now, we mention two other points with respect to moral obligations. First, the place of moral obligations in Arrow is crucially different from that in Rawls. In Rawls's framework, moral obligations would be determined after the concrete principles of justice have been accepted by citizens in society. In contrast, Arrow considers that there exists some moral obligations prior to making social values and justice. Pre-existing moral obligations among people can have a significant role in collective decision-making.

Second, it is noteworthy that moral obligations can be those which people unintentionally follow. We can regard moral codes and social norms as a part of spontaneous order: people behave as if codes and norms are given exogenously. They are beyond individuals, but they can be a consequence of evolutionary and dynamic processes. These ideas are consistent with Arrow's two resolutions of the impossibility theorem, domain restriction and extended sympathy, because the restriction on preferences and the form of sympathy are not an object of collective decision-making, and are given for each individual. A certain preference restriction or sympathy is pre-existing among individuals.

Like the communitarians, Arrow attaches importance to history: "In view of the uncertainty as to the future, this means that institutions at any moment represent adaptations in part to past conditions, not present ones. History therefore matters" (Arrow, 1998, p 39). Moral obligations and social norms are regarded as institutions and formulated as accumulations of actions and decision makings in the past. Moreover, Arrow (1973) argues that the original position does not provide a foundation for social justice. All 
individuals are assumed to know and agree with social facts in the original position. This leads us to a difficulty. Arrow's point is toleration. He writes: "I am in favor of very wide toleration. But I am not convinced that the original position is a sufficient basis for this argument, for it transfers the problem to the area of factual disagreement" (Arrow, 1973, p. 255). Social facts are not obvious. ${ }^{17}$ Thus, individuals who have history believe in some particular social facts, and they cannot imagine a person in the original position. To some extent, Arrow might agree with the communitarians about the over-individualization of the original position. Indeed, when he criticizes the original position, what Arrow cares about is the conception of individual:

"To the extent that individuals are really individual, each an autonomous end in himself, to that extent they must be somewhat mysterious and inaccessible to each other. There cannot be any rule that is completely acceptable to all. There must, or so it now seems to me, be the possibility of unadjudicable conflict" (Arrow, 1973, p. 263).

According to Arrow, "individuals in a society are not atoms but interlinked in many ways" (Arrow, 1967, p. 737). An individual in the society is not isolated: the others are fundamentally important to make his/her action. As a result, Arrow seems close to the communitarians even though it is worth recalling that the conception of "individual" does not mean less than it does in Arrow's views: the individual is more than a mere member of a community.

Recall that moral obligations are crucial for overcoming an "unadjudicable conflict". Moreover, the moral codes and obligations are devises for internalizing other regarding concerns. Arrow thinks that there is no possibility of social justice without moral obligations. The following sentences suggest that religion is a potential source of moral obligations:

"[P] eople do have aims in life, and not just the grand achievement of material gains. They're concerned about others. This concern is the result of moral codes, which are developed and

${ }^{17}$ He writes:

"Operationally, a Catholic would have to recognize that in the original position he wouldn't know he would be a Catholic and would therefore have to tolerate Protestants or Jews or whatever, since he might well have been one. But suppose he replies that in fact Catholicism is the true religion, that it is part of the knowledge which all sensible people are supposed to have in the original position, and that he insists on it for the salvation of all mankind. How could this be refuted?" (Arrow, 1973, p. 255) 
adopted through religion or through inculcation by other ethical sources" (Arrow, 2006, p. 3).

Given that religion is a typical source of common good for the communitarians, Arrow seems to take a similar position to that of the communitarians in a relationship with Rawlsian theories of justice.

Moreover, this view of individuals is at the core of Arrow's thinking about equality. First, we should notice that Arrow does not propose a concrete idea of equality:

"I believe strongly in the fundamental desirability of equality and even a fairly rigid version of it with regard to income. But I must confess that I cannot define the exact meaning of equality. But this lack of definiteness need to prevent discussion of the broad issues" (Arrow, 1985, p. 91).

Instead of introducing a concrete concept of equality, Arrow proposed two principles of equality. The first one is "the productivity principle (that an individual is entitled to what he creates" (Arrow, 1985, p. 146). This principle is clearly a variation of the Lockean proviso. This principle is based on the idea that each person owns his/her talent. Note that one of the goals of a market is to achieve this principle. However, this principle is unjust because, according to Arrow (1985), (a) people are a product of society, and thus, their responsibility must be nuanced and (b) each individual's natural talent must be used for the society, not for him or her (in other words, people do not deserve their natural talent).

This argument leads him to the second principle: "the redistributionist principle (that even natural advantages and superiorities do not in themselves create any claims to greater rewards)" (Arrow, 1985, p. 146). ${ }^{18}$ Clearly, Arrow put his emphasis on this principle, which is based on the idea that talents of individuals are common assets in the society. Interestingly, he also associate the second principle with moral obligations: "inequality in the possession of natural productive assets simply creates a moral obligation on the part of the better endowed to use their talents for the common good" (Arrow, 1985, p. 146). This is particularly true for people with higher education. Arrow writes:

\footnotetext{
${ }^{18}$ In a review of $A$ Theory of Justice, Arrow (1973) argues that Rawls's fundamental assumption is asset egalitarianism: "that all the assets of society, including personal skills, are available as a common pool for whatever distribution justice calls for, is so much taken for granted that it is hardly argued for." Asset egalitarianism is the idea behind the redistributionist principle. Thus, it is safe to say Arrow partialy agrees with the Rawlsian conception of equality.
} 
"The university graduates must develop an ethos of social stewardship. Their superior natural talents, enhanced by the university, have to be thought of as held in trust for the average and especially for the disadvantaged. This is first and foremost a matter of values to be held by the graduates, although there may be more specific requirements to be prescribed by society" (Arrow, 1993, p. 12).

Highly educated people with talents have social responsibility. Their existence naturally generates a social pressure toward inequality, but it must be partially neutralized by their moral concerns. In this sense, moral obligations are quite necessary for good societies.

We mention two points. First, there can be a conflict between the two principles. This is because if we introduce the government intervention to follow the redistributionist principle, then the productivity principle should be violated. However, Arrow claims that the two are "not completely incompatible" (Arrow, 1986, p. 146). If people have moral obligations, people with high income voluntarily feel it is better to redistribute from them to the poor. Under such circumstances, the two principles are compatible. Second, the importance of moral obligations can explain vagueness of the concept of equality. Moral obligations are dependent on ethical sources. This means that there is no universal and unique treatment of norms, as in the case of the communitarians. ${ }^{19}$ That is, there is necessarily no concrete concept of equality, which is linked with moral obligations.

A system of moral obligations works not only as a function for formulating social values but also as a mechanism for helping to achieve social values. That is, moral obligations are not fundamentally linked to the economic or political world but rather, they make us to achieve a better outcome in terms of given social values. The fact that some economic sectors work well inside or outside of a market mechanism shows that moral obligations might be deeply relevant in the conduct of economic and social activities. In the case of social capital for instance, Arrow (2000) deals with social capital mostly the idea that pre-existing network affecting economic performance outside the market and its system of prices. In this regard, religion (Weber) and trust (Putnam) are typical examples of networks that interfere with efficiency even though at first glance it has nothing to see in itself with economic performance. However, the working of moral obligations in actual economic

\footnotetext{
${ }^{19}$ The following sentense by Arrow suggests that each society has its own system of moral obligations: "any society, democratic or not, must have as a root element degree of mutual obligation and some sense of respect for every individual, however low he may wind up in the hierarchy" (Arrow, 1985, p. 144).
} 
life is not obvious. What is the relationship of moral obligations with markets or governments. In the next section, we investigate how obligations and norms can work in such economic organizations.

\section{Moral Obligations, Market, and Govern- ment}

The theory of general equilibrium (GE), which is developed by Arrow and other economists, shows the limitation of a market as an organization (Arrow, 1974a). That is, GE shows what the market cannot do as well as what it can. Moreover, one big achievement of GE is showing crucial postulates, which are needed for markets to be working well. Then, the limitation is associated with fundamental welfare theorems, which state that a Walrasian allocation is associated with a Pareto efficient allocation only under "certain postulates." First, there is the possibility that competition cannot yield market equilibrium. Second, if there are external effects or asymmetric information among economic agents, a market cannot achieve Pareto efficiency. This lack of efficiency is possible even if a market equilibrium is achieved. Third, there exists no guarantee that a market allocation is equitable. In other words, the equity problem can occur even if the market is completely operational and achieves a Pareto-efficient allocation. Thus, there are various types of market failure.

People who believe markets in fundamentalism might argue that the first and second problems are less likely, and the third problem does not matter (i.e., inequity of allocation should be left as is). ${ }^{20}$ Once property rights are given, people can negotiate with each other, and the process of negotiation can yield efficient outcomes if there is no transaction cost (Edgeworth's convergence theorem and the Coase (1960) theorem). ${ }^{21}$ That is, a market can

\footnotetext{
${ }^{20}$ For example, Coase (1960) argues that even if there is an external effect, a market mechanism can achieve an efficient outcome through bargaining if there is no transaction costs. Friedman (2009 [1962]) claims that a main cause of monopoly is government intervention (thus, monopoly is less possible in a "free" market society).

${ }^{21}$ Edgeworth's convergence theorem states that the core converges to a Walrasian outcome. The original proof is given by Edgeworth (1881). Debreu and Scarf (1963) show the convergence theorem in a rigorous way. The core, the set of allocations that cannot be improved by any coalition in an economy, can be regarded as an outcome of decentralized transactions, which are also fundamental factors of Coase's approach. The point is that contrary to a Walrasian centralized transaction process, both Edgeworth and Coase consider a decentralized bargaining process without a transaction cost. Indeed, replying criticism of Paul Samuelson, Coase (1988) confessed that the idea of the Coase theorem comes from Edgeworth's argument.
} 
achieve a satisfactory allocation for the people. Arrow himself is skeptical with such a view (Arrow [1969] 1983, 1972, [1979] 1994). ${ }^{22}$ It is not easy to achieve either efficient or equitable allocations in a market. ${ }^{23}$

A central question of modern welfare economics is as follows: is there any prescription for these problems of market economies? The textbook answer is government intervention. The problem of price adjustment can be partially resolved by incorporating planning. Moreover, taxation and redistribution can resolve not only the efficiency problem but also the equity problem. That is, the problems are overcome by designing formal mechanisms. This predisposition toward the intervention can be traced back to Pigou's "old" welfare economics.

However, Hayek (1948) opposes the interventionist view. For Hayek (1948), this view is based on an over-rationalized (i.e., Rational with capital "R" for Hayek) concept of a person or an individual. Each person has a limitation of ability and cannot control the activities of a government. Only markets and conventions are institutions that people can rely on.

Contrary to Hayek, Arrow does not strongly oppose interventions by the government. However, government intervention does not seem to be his first choice. Like Hayek, Arrow emphasizes the role of moral judgments among people, such as trust, social norms, obligations, and responsibility. This position of Arrow comes from his fundamental thinking about the nature of the price system. Arrow (1972) writes:

"Property systems are in general not completely self-enforcing. They depend for their definition upon a constellation of legal procedures, both civil and criminal. The course of the law itself cannot be regarded as subject to the price system. The judges and the police may indeed be paid, but the system itself would disappear if on each occasion they were to sell their services and decisions. Thus the definition of property rights based on the price system depends precisely on the lack of universality of private property and of the price system. ...The price system is not,

\footnotetext{
${ }^{22}$ Arrow ([1969] 1983) is originally published in: The analysis and evaluation of public expenditure: the PPB system, (1969), 1, 47-64. Arrow ([1979] 1994) is originally published in: Adam Smith and Modern Political Economy, G. P. O’Driscoll, Jr. (eds.), Ames : Iowa State University Press, 1979, 153-164.

${ }^{23} \mathrm{~A}$ lot of definitions of equity have been given in the theory of fairness. There two distinct concept of equity, envy-freeness and egalitarian equivalence. The first one requires that no individual prefers someone's bundle to his/her own bundle. The second one requires that there is a reference bundle such that for everyone, his/her own bundle is indifferent to the reference. For detailed arguments on them and other concepts, see Thomson (2011).
} 
and perhaps in some basic sense cannot be, universal. To the extent that it is incomplete, it must be supplemented by an implicit or explicit social contract" (Arrow, 1972, p. 357).

Arrow's thinking is remarkable in two respects. First, Arrow is concerned with not just market failure but also alternative systems. ${ }^{24}$ Common property rights were more common in the Middle Ages, but are still effective in many economies. Moreover, an allocation based on orders and commands are extremely natural in most economic organizations. In such organizations, orders and commands are signals made by the top of a hierarchy, and these are sequentially sent to successors. This system was widespread in the Middle Ages with a connection with loyalty, and it is still a main mechanism for determining allocations in firms. Also, customs and morals can affect allocation in organizations or societies. Therefore, customs and morals are also alternative systems of allocations or they can complement/limit other systems. In particular, many sociological and anthropological studies have demonstrated that an economy with gift exchanges works effectively in societies without well-developed property rights. In such an economy, people cannot exchange goods anonymously without caring about social relationships. In these systems, obligation, norms, loyalty, orders work as signals for allocations, like prices do in a market.

The second noteworthy aspect of Arrow's thinking is that he does not consider the market as autonomous; it must be complemented by other systems and signals. In addition, he also mentions "implicit social contracts" as well as explicit laws and orders. Indeed, Arrow emphasizes the role of such implicit obligations and norms in many places. ${ }^{25}$ According to Arrow ([1969] 1983),

\footnotetext{
${ }^{24}$ Arrow ([1979] 1994) explicitly mentions the possibility of alternative systems by criticizing Adam Smith's thought: "The market is a very important coordinating mechanism but it is by no means the only one; in the social sphere as a whole it is simply one among many" (Arrow, [1979] 1994, p. 74).

${ }^{25}$ For example, Arrow writes:

"[T] hus there are two types of situation in which the simple rule of maximization profits is socially inefficient: the case in which costs are not paid for, as in pollution, and the case in which the seller has considerably more knowledge about his product than the buyer, particularly with regard to safety. In these situations it is clearly desirable to have some idea of social responsibility, that is, to experience an obligation, whether ethical, moral, or legal. Now we cannot expect such an obligation to be created out of thin air. To be meaningful, any obligation of this kind, any feeling or rule of behavior has to be embodied in some definite social institution" (Arrow, [1973] 1985, pp. 135-136).
} 
"I suggest as one possible interpretation that they are reactions of society to compensate for market failures. It is useful for individuals to have some trust in each other's word. In the absence of trust, it would become very costly to arrange for alternative sanctions and guarantees, and many opportunities for mutually beneficial cooperation would have to be foregone" (Arrow, [1969] 1983, p. 151).

These moral judgments can resolve market failures in a certain way.

How do moral judgments work exactly? In 1963, Arrow wrote a pathbreaking paper on moral hazard (Arrow, 1963b). Let us consider that a person (the principal) has asked another person (the agent) to do something for him or her. The agent's action is made after their contract, and it is hidden (private) information from the principal. Since there is no way to sanction the agent directly, there exists no incentive for the agent to make an effort. Efficiency is sacrificed if the agent shirks. This problem is known as moral hazard, and has been developed after Arrow (1963b). Moral hazard can be found in many economics circumstances: the employer-worker relationship, the bank-firm relationship, the investor-chief executive officer relationship, and so on. Arrow (1963b, 2001) himself focuses on a medical market, especially, the case where the principal is a patient and the agent is a physician: when the physician makes a surgery for the patient, the patient cannot know the quality of the surgery. ${ }^{26}$ Then, "the customer cannot test the product before consuming it, and there is an element of trust in the relation" (Arrow, 1963b, p. 949). ${ }^{27}$ Therefore, the patient needs to trust the physician, while the physician has an obligation on his treatment. ${ }^{28}$ Trust can be a demand of the physician as well:

"[T]he physician wants an ethical code to act as assurance to the buyer, and he certainly wants an ethical code to obey this same code, partly because any violation may put him at a disadvantage but more especially because the violation will reflect on him, since the buyer of the medical services may not be able

\footnotetext{
${ }^{26}$ See especially pp. 961-962 of Arrow (1963b).

${ }^{27}$ Arrow also (1963b, p. 949) wrote: "the ethically understood restrictions on the activities of a physician are much more severe than on those of, say, a barber. His behavior is supposed to be governed by a concern for the customer's welfare which would not be expected of a salesman. In Talcott Parsons's terms, there is a "collectivity-orientation," which distinguishes medicine and other professions from business, where self-interest on the part of participants is the accepted norm."

${ }^{28}$ Arrow (1996) discusses how information affects obligations in the context of the physician-patient relationship.
} 
to distinguish one doctor from another" (Arrow, [1973] 1985, p. 140).

These non-market factors are fundamental for the function of this market.

According to Arrow (2000), "the market needs supplementations (for efficiency) by nonmarket relations" (Arrow, 2000, p. 5). Then moral obligations are an important part of market functioning. Arrow ([1969] 1983) writes:

"[I]t is difficult to conceive of buying trust in any direct way (though it can happen indirectly, for example, a trusted employee will be paid more as being more valuable); indeed, there seems to be some inconsistency in the very concept. Nonmarket action might take the form of a mutual agreement. But the arrangement of these agreements and especially their continued extension to new individuals entering the social fabric can be costly. As an alternative, society may proceed by internalization of these norms to the achievement of the desired agreement on an unconscious level. There is a whole set of customs and norms which might be similarly interpreted as agreements to improve the efficiency of the economic system (in the broad sense of satisfaction of individual values) by providing commodities to which the price system is inapplicable" (Arrow, [1969] 1983, p. 152).

Related arguments are presented by Akerlof (1982) and Akerlof and Kranton (2010). They find a significant role of the gift-exchange relationship and identities embedded in organizations. It is obvious that if people care about only monetary motivations, incentive wages are better than fixed wages. However, fixed wages are widespread in many countries. This means that another concern arises. In addition, monitoring can ruin motivation of workers. These embedded relationships can enhance not only efficiency but also equity in the society. ${ }^{29}$ This is because workers are deeply concerned with fairness of what job is assigned to them and what they receive. To sum up, there are two moral concerns supplementing markets: the equity-improving effect of concerns about fairness and the efficiency-improving role of trust. He wrote: "[e]thical codes have mutual value because on the one hand they avoid exploitation and on the other they avoid distrust" (Arrow, [1979] 1994, p. 80).

However, this does not mean that any system of moral obligations is beneficial for the society. Obviously, there can be substitution and complementary between norms and obligations. Therefore, a combination of norms and obligations is important to enhance social justice. Moreover, some norms are

\footnotetext{
${ }^{29}$ Arrow writes: "I take very seriously the moral obligation to achieve equity in income, now and in the future" (Arrow, [1979] 1983, p. 200).
} 
very harmful for social justice. Many types of discrimination, which make a society inefficient and unequal, come from traditional social norms in current societies.

The problem is whether processes of social evolution can lead people to morals and norms, which entail just allocations. Such a nice convergence might not be achieved in the long run. Let us consider a coordination game. An evolutionary stable strategy (ESS) cannot eliminate an inefficient outcome. A more illustrative example is the role of religions in the theories of Max Weber. According to him and other socio-economists, some norms associated with religions can affect the development of economies. This implies that different religions can lead to different types of economic developments. Weber's theory about the role of Protestantism that there are multiple convergent points of social norms, which can affect economic outcomes. This is quite a controversial view, although it is compelling.

ESS is not a unique approach to social evolution. Some other concepts of equilibrium, such as risk dominance, are more likely to achieve an efficient outcome. However, even in that case, there is no guarantee of achieving equity. ${ }^{30}$ Thus, some actions by a government or third party are needed to coordinate norms and morals. That is, governing moral obligations and social norms can be a fundamental role of the government.

In order to see how the government works for social norms, let us take the case of social capital, which has been discussed widely by social scientists recently. Social capital is a form of capital associated with trust and reciprocity in a society. It forms a part of social norms. According to Arrow (2000), the main claim of social capital approach is that "membership in associations strengthens political and economic efficiency even though the associations themselves play no role in either the polity or the economy" (Arrow, 2000, p. 4). Any type of economic policy potentially affects social capital:

"[I]t may be more fruitful to think of the existing social relations as a preexisting network into which new parts of the economy (for example, development projects) have to be fitted. We would want to fit new projects so as to exploit complementary relations and avoid rivalries. Of course, new projects will create

\footnotetext{
${ }^{30}$ On the links between norms and efficiency, Eslter (1989) acknowledges that Arrow is "the most articulate and explicit" (Elster, 1989, p. 108). Nevertheless, Elster disagrees with Arrow: "First, not all norms are Pareto-improvements. Some norms make everybody worse off, or, at the very least, they do not make almost everybody better off. Secondly, some norms that would make everybody better off are not in fact observed. Thirdly, even if a norm does make everybody better off, this does not explain why it exists" (Eslter, 1989, p. 108).
} 
their own unintended social relations, possibly destroying existing ones" (Arrow, 2000, p. 4).

The key point is that norms and morals are "pre-existing." Policies "have to be fitted" into pre-existing norms and obligations. As mentioned before, monitoring and punishment can ruin loyalty or identities of workers in work places. Thus, monitoring is harmful under some pre-existing network. On the other hand, monitoring and punishment work effectively in some culture. ${ }^{31}$ Therefore, the performance of such strict policies is dependent on pre-existing norms. There is an interaction between preexisting network and economic policies because the situation created by economic policies can affects norms and morals in the long run. In a joint work with Arrow, Kinzig et al. (2013) write:

"Policies can become more cost effective in the long run if they feedback to influence social norms, so that behaviors become self-reinforcing even in the absence of external regulations or penalties. We know that values influence behaviors. What policymakers need to exploit is that behaviors can also influence values" (Kinzig et al., 2013, p. 168).

There are several ways of governing social norms. In the context of environmental governance, Kinzig et al. (2013) mention four approaches: regulation, financial interventions, active norms management, and changing architecture. The first two approaches are quite traditional in welfare economics. The last two are more recent and based on nudging. In active norms management, social norms are supposed to be improved trough advertising and information blitzes. Health in Japan is a good example of this approach (Borovoy and Roberto, 2015). Life expectancy is highest in all countries and obesity is very low, but there is no strict regulation on food or health. There is a lot of advertising and educational information in schools and companies in Japan. Changing architecture attempt to change people's behavior by making good behavior "convenient" and "visible".

However, a policy-maker must take irreversibility of social norms and moral obligations seriously. This is a fundamental nature of "nominal" values. In this respect, norms and obligations are quite similar to money and stock values. In particular, there has been no fundamental value of money after the gold standard was abandoned. A value of money is determined by the "belief" of people in a society. Like other nominal values, social norms

\footnotetext{
${ }^{31}$ Yamagishi (1988) shows that monitoring and punishment have a positive effect in Japanese cultures.
} 
and moral obligations are based on people's belief, and thus, they share a irreversibility property with money.

For example, trust, which is a form of social capital, is gradually fostered by people. An intervention by the government could be harmful or even destroy trust among people. Indeed, a famous example is a kinder garden of Israel. Gneezy and Rustichini (2000) show the working of social norms. They introduce a small fine for parents who are late to pick up their children. The number of late parents is increased after the introduction of the fine. After getting rid of this fine, the rate of late parents does not return to the original rate. An interpretation of this result is moral concerns are replaced by monetary concerns. First, simulating monetary concerns can destroy concerns about the current social norms. Once social norms are destroyed, it is not easy to return the previous situation. In this sense, social norms and obligations are vulnerable. This implies that the government intervention without a close looking is quite risky and even harmful.

\section{Concluding Remarks}

In one of recent interviews, Arrow says: "to say I'm interested in ethics is probably just to say I'm a human being... The real issue is whether you think about ethical concerns rather than just accept them" (Arrow, 2017 p. 89). What we tried in this paper is showing the entire picture of ethical concerns. In particular, we examined the role of moral obligation in formulating and practicing social justice through a series of works of Arrow. We found a consistent and comprehensive view on norms and obligations in his works. In his theory, the underlying interaction among human behaviour and moral judgments is complicated, but it is very systematic and structured. Figure 1 shows how moral obligations and social norms work in Arrow's considerations.

[Figure 1 is around here...]

Moral obligations have the fundamental role in a society. At each point of time, they are given to people in the society, and they help formulating social values and obtaining the principle of justice, which provide the objective function for the government. This is the role of moral obligations in normative aspects (the upper half of Figure 1). On positive sides, moral obligations restrict people's actions. An important thing is that there is not only a short-run interaction between obligations and public policies but also a long-run feedback. The lower half of Figure 1 is associated with how positive sides works. Moreover, this long-run feedback involves the normative 
side because social values can affect a sense of justice of people. The entire process is rather an evolutionary process than a social contract.

When we consider Arrow's thinking as a theory of justice, his approach is rather that of communitarian. In all of his works, Arrow keeps Paretian efficiency as a fundamental value for society. This implies that welfarism holds. $^{32}$ We may call Arrow's position welfarist communitarian. This gives us a totally different perspective from that of Rawls and Sen, which are quite influential for contemporary political philosophy and social choice theory. Hopefully, his welfarist-communitarian approach is an alternative method for making compelling public policies.

\section{Figure}

\section{References}

[1] Akerlof, G. A. 1982. Labor contracts as partial gift exchange. The Quarterly Journal of Economics 97(4): 543-569.

[2] Akerlof, G. A. and R. E. Kranton. 2010. Identity Economics: How Identities Shape Our Work, Wages, and Well-Being. Princeton: Princeton University Press.

[3] Anderson, B. 1991. Imagined Communities: Reflections on the Origin and Spread of Nationalism. New York: Verso.

[4] Andreoni, J. 1990. Impure altruism and donations to public goods: A theory of warm-glow giving. The Economic Journal 100(401): 464-477.

[5] Arrow, K. J. 1963a. Social Choice and Individual Values. Second edition. New York: Wiley.

[6] Arrow, K. J. 1963b. Uncertainty and the welfare economics of medical care. The American Economic Review 53(5): 941-973.

[7] Arrow, K. J. 1967. Samuelson collected. Journal of Political Economy $75(5): 730-737$

\footnotetext{
${ }^{32}$ Sen (1979) proved that welfarism follows from the Pareto principle and IIA in the Arrovian framework. Thus, Paretian efficiency restricts the use of information and makes social judgments to be based on welfarism. Later, Kaplow and Shavell (2001) directly showed that welfarism is implied by the Pareto principle in the Bergson-Samuelson framework (by assuming continuity of a social welfare function).
} 
[8] Arrow, K. J. [1967] 1983. The place of moral obligation in preference systems. In Collected Papers of Kenneth J. Arrow. Vol. 1: Social Choice and Justice, 78-80. Cambridge: Harvard University Press.

[9] Arrow, K. J. [1969] 1983. The organization of economic activity: issues pertinent to the choice of market versus non-market allocations. In Collected papers of Kenneth J. Arrow. Vol. 2: General equilibrium, 133-155. Cambridge: Harvard University Press.

[10] Arrow, K. J. 1972. Gifts and exchanges. Philosophy \& Public Affairs 1(4): $343-362$.

[11] Arrow, K. J. 1973. Some ordinalist-utilitarian notes on Rawls's theory of justice. Journal of Philosophy 70(9): 245-263.

[12] Arrow, K. J. [1973] 1985. Social responsibility and economic efficiency. In Collected Papers of Kenneth J. Arrow. Vol. 6: Applied Economics, 130-142. Cambridge: Harvard University Press.

[13] Arrow, K. J. 1974a. The Limits of Organization. New York: Norton.

[14] Arrow, K. J. 1974b. General economic equilibrium: purpose, analytic techniques, collective choice. The American Economic Review 64(3): 253272.

[15] Arrow, K. J. 1977. Current developments in the theory of social choice. Social Research 44(4): 607-622.

[16] Arrow, K. J. [1979] 1983. The trade-off between growth and equity. In Collected Papers of Kenneth J. Arrow. Vol. 1: Social Choice and Justice, 190-200. Cambridge: Harvard University Press.

[17] Arrow, K. J. [1979] 1994. The division of labor in the economy, the polity, and society. In The Return to Increasing Returns, ed. J. M. Buchanan, and Y. J. Yoon, 69-84. Ann Arbor: The University of Michigan Press.

[18] Arrow, K. J. 1983. Collected Papers of Kenneth J. Arrow, Vol 1.: Social Choice and Justice. Cambridge: Harvard University Press.

[19] Arrow, K. J. 1985. Distributive justice and desirable ends of economic activity. In Issues in Contemporary Macroeconomics and Distribution, ed. G.R. Feiwel, 134-156. Albany: State University of New York Press.

[20] Arrow, K. J. 1993. Excellence and equity in higher education. Education Economics 1(1): 5-12. 
[21] Arrow, K. J. 1996. Information, responsibility, and human services. In Individual and Social Responsibility: Child Care, Education, Medical Care, and Long-Term Care in America, ed. V.R. Fuchs, 229-244. Chicago: University of Chicago Press.

[22] Arrow, K. J. 1998. The place of institutions in the economy: a theoretical perspective. In The Institutional Foundations of East Asian Economic Development: Proceedings of the IEA Conference held in Tokyo, Japan, ed. Y. Hayami and M. Aoki, 39-48. Basingstoke: Macmillan.

[23] Arrow, K. J. 2000. Observations on social capital. In Social Capital: A Multifaceted Perspective, ed. P. Dasgupta, and I. Serageldin, pp. 3-5, Washington: World Bank.

[24] Arrow, K. J. 2001. Reflections on the reflections. Journal of Health Politics, Policy and Law 26(5): 1197-1203.

[25] Arrow, K.J. 2006. The economy of trust. Religion and Liberty 16(3): 3 and $12-13$.

[26] Arrow, K. J. 2017. On Ethics and Economics: Conversations with Kenneth J. Arrow. Oxon: Routledge.

[27] Bergson, A. 1938. A reformulation of certain aspects of welfare economics. The Quarterly Journal of Economics 52(2): 310-334.

[28] Bergson, A. 1954. On the concept of social welfare. The Quarterly Journal of Economics 68(2): 233-252.

[29] Binmore, K. 2005. Natural Justice. Oxford: Oxford University Press.

[30] Black, D. 1948. On the rationale of group decision-making. The Journal of Political Economy 56(1): 23-34.

[31] Black, D. 1958. The Theory of Committees and Elections. Cambridge: Cambridge University Press.

[32] Blau, J. H. 1957. The existence of social welfare functions. Econometrica 25(2): 302-313.

[33] Borovoy, A. and C. A. Roberto. 2015. Japanese and American public health approaches to preventing population weight gain: A role for paternalism?. Social Science $\&$ Medicine 143: 62-70. 
[34] Bowles, S. 2016. The Moral Economy: Why Good Incentives are No Substitute for Good Citizens. London: Yale University Press.

[35] Campbell, D. E., and J. S. Kelly 2000. Information and preference aggregation. Social Choice and Welfare 17(1): 3-24.

[36] Cato, S. 2014. Independence of irrelevant alternatives revisited. Theory and Decision 76(4): 511-527.

[37] Coase, R. 1960. The problem of social cost. Journal of Law and Economics 3: 1-44.

[38] Coase, R. 1988. The Firm, the Market, and the Law. University of Chicago Press.

[39] Debreu, G. and H. Scarf. 1963. A limit theorem on the core of an economy. International Economic Review 4(3): 235-246.

[40] Edgeworth, F. Y. 1881. Mathematical Psychics: An Essay on the Application of Mathematics to the Moral Sciences. London: C. K. Paul.

[41] Elster, J. 1989. Social norms and economic theory. Journal of Economic Perspectives 3(4): 99-117.

[42] Fehr, E. and K. M. Schmidt. 2006. The economics of fairness, reciprocity and altruismexperimental evidence and new theories. In Handbook of the Economics of Giving, Altruism and Reciprocity, ed. S.-C. Kolm, and J. M. Ythier, vol 1, 615-691. Amsterdam: Elsevier.

[43] Fleurbaey, M. and F. Maniquet. 2011. A Theory of Fairness and Social Welfare. Cambridge: Cambridge University Press.

[44] Fleurbaey, M. and P. Mongin. 2005. The news of the death of welfare economics is greatly exaggerated. Social Choice and Welfare 25(2-3): 381-418.

[45] Fleurbaey, M., K. Suzumura, and K. Tadenuma 2005. Arrovian aggregation in economic environments: How much should we know about indifference surfaces?. Journal of Economic Theory 124(1): 22-44.

[46] Friedman, M. 2009 [1962]. Capitalism and Freedom. Chicago: University of Chicago Press.

[47] Gneezy, U. and A. Rustichini. 2000. A fine is a price. The Journal of Legal Studies 29(1): 1-17. 
[48] Hammond, P. J. 1976. Equity, Arrow's conditions, and Rawls' difference principle. Econometrica 44(4): 793-804.

[49] Harsanyi, J. C. 1953. Cardinal utility in welfare economics and in the theory of risk-taking. Journal of Political Economy 61(5): 434-435.

[50] Hayek, F.A. 1948. Individualism and Economic Order. Chicago: University of Chicago Press.

[51] Hicks, J. R. 1939. The foundations of welfare economics. The Economic Journal 49(196): 696-712.

[52] Hook, S. 1967. Human Values and Economic Policy. New York: New York University Press.

[53] Inada, K. I. 1969. The simple majority decision rule. Econometrica 37(3): 490-506.

[54] Kaldor, N. 1939. Welfare propositions of economics and interpersonal comparisons of utility. The Economic Journal 49(195): 549-552.

[55] Kaplow, L., Shavell, S. 2001. Any non-welfarist method of policy assessment violates the Pareto principle. Journal of Political Economy, 109(2), 281-286.

[56] Kelly, J. S. 1987. An interview with Kenneth J. Arrow. Social Choice and Welfare 4(1): 43-62.

[57] Kinzig, A. P., P. R. Ehrlich, L. J. Alston,K. Arrow, S. Barrett, T. G. Buchman, B. Levin, S. Levin, M. Oppenheimer, E. Ostrom, and D. Saari. 2013. Social norms and global environmental challenges: the complex interaction of behaviors, values, and policy. BioScience 63(3): 164-175.

[58] Konow, J. 2003. Which is the fairest one of all? A positive analysis of justice theories. Journal of Economic Literature 41(4): 1188-1239.

[59] Kramer, G. H. 1973. On a class of equilibrium conditions for majority rule. Econometrica 41: 285-297.

[60] Little, I. M. 1952. Social choice and individual values. The Journal of Political Economy 60(5): 422-432.

[61] Putnam, R. D. 2001. Bowling Alone: The Collapse and Revival of American Community. New York: Simon and Schuster. 
[62] Rawls, J. 1971. A Theory of Justice. Cambridge: Harvard university press.

[63] Samuelson, P. A. 1967. Arrow's mathematical politics. In Human Values and Economic Policy, ed. S. Hook, 41-51. New York: New York University Press.

[64] Samuelson, P. A. 1983. The Foundations of Economic Analysis: Enlarged Edition. Cambridge: Harvard University Press.

[65] Sandel, M. J. 1982. Liberalism and the Limits of Justice. Cambridge: Cambridge University Press.

[66] Sen, A. and P. K. Pattanaik. 1969. Necessary and sufficient conditions for rational choice under majority decision. Journal of Economic Theory 1(2): 178-202.

[67] Sen, A. 1970. The impossibility of a Paretian liberal. Journal of Political Economy 78(1): 152-157.

[68] Sen, A. 1979. Personal utilities and public judgements: or what's wrong with welfare economics. The Economic Journal, 89(355), 537-558.

[69] Sen, A. 1980. Equality of what? In Tanner Lectures on Human Values, Volume 1, ed. S. McMurrin. Cambridge: Cambridge University Press.

[70] Sen, A. 1987. On Ethics and Economics. New York: Wiley-Blackwell.

[71] Sen, A. 1999. Reason before Identity. Oxford: Oxford University Press.

[72] Sen, A. 2009. The Idea of Justice. Cambridge: Harvard University Press.

[73] Suzumura, K. 2002. Introduction, In Handbook of Social Choice and Welfare, Vol. 1, ed K. J. Arrow, A. K. Sen, K. Suzumura, 1-32. Amsterdam: Elsevier.

[74] Suzumura, K. 2005. An interview with Paul Samuelson: welfare economics, "old" and "new", and social choice theory. Social Choice and Welfare 25(2-3), 327-356.

[75] Suppes, P. 1966. Some formal models of grading principles. Synthese 16(3): 284-306.

[76] Thomson, W. 2011. Fair allocation rules. In: K.J. Arrow, A.K. Sen, K. Suzumura (eds) Handbook of Social Choice and Welfare, Vol. 2, pp. 393-506, Elsevier. 
[77] Yamagishi, T. 1988. The provision of a sanctioning system in the United States and Japan. Social Psychology Quarterly 51(3): 265-271.

[78] Vickrey, W. 1945. Measuring marginal utility by reactions to risk. Econometrica 13(4): 319-333. 
Figure 1: The role of moral obligations

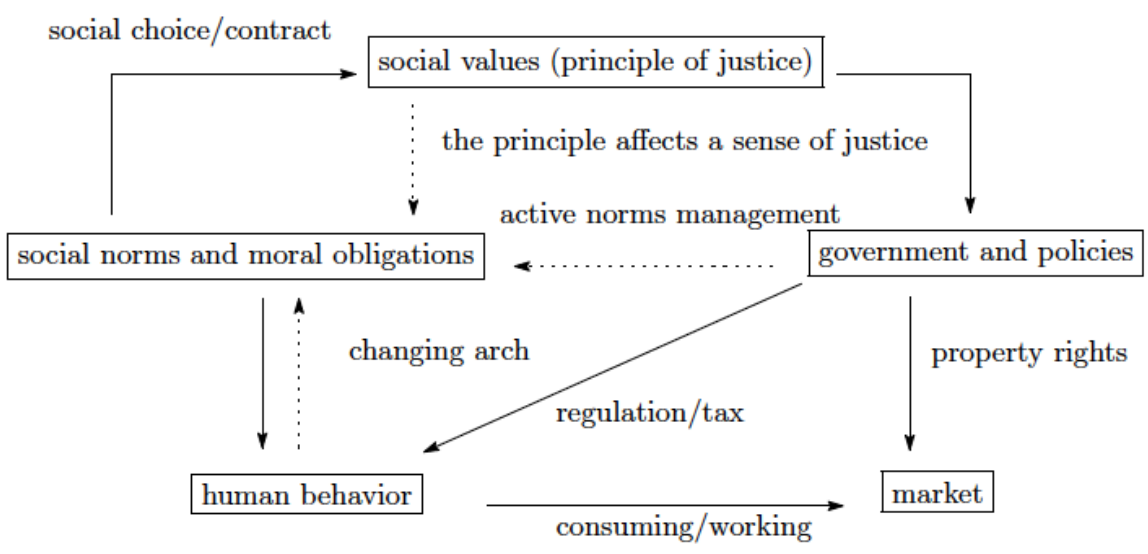

Figure 1: the interaction: "dots" line shows the long-run effect 